Replacement of Dietary Fish Oil with Increasing Levels of Linseed Oil: Modification of Flesh Fatty Acid Compositions in Atlantic Salmon (Salmo salar) Using a Fish Oil Finishing Diet.

J.Gordon. Bell*, R.James. Henderson, Douglas.R. Tocher and John.R. Sargent. Lipid Nutrition Group, Institute of Aquaculture, University of Stirling, FK9 4LA, Scotland, U.K.

Running title; FLESH FATTY ACID COMPOSITIONS IN ATLANTIC SALMON

Corresponding author; Dr J.G. Bell, Lipid Nutrition Group, Institute of Aquaculture, University of Stirling, Stirling FK9 4LA, Scotland, U.K. Tel. 441786 467997; Fax. 44 1786 472133; email g.j.bell@stir.ac.uk. 
1 *To whom all correspondence should be addressed at Lipid Nutrition Group, Institute of

2 Aquaculture, University of Stirling, Stirling FK9 4LA, Scotland, U.K.

3 Abbreviations: DHA, docosahexaenoic acid; EPA, eicosapentaenoic acid; FO, fish oil;

4 HUFA, highly unsaturated fatty acid; LO, linseed oil. 
1 ABSTRACT: Five groups of Atlantic salmon smolts, of initial mean weight $127 \pm 3 \mathrm{~g}$,

2 were fed increasing levels of dietary linseed oil (LO) in a regression design. The control

3 diet contained capelin oil (FO) only and the same oil was blended with LO to provide the

4 experimental diets. After an initial growth period of 40 weeks all treatment groups were

5 switched to a finishing diet containing only FO for a further 24 weeks. Growth, flesh total

6 lipid content and astaxanthin content were not affected by dietary oil composition. The

7 fatty acid compositions of flesh total lipids were linearly correlated with dietary fatty acid

8 compositions $\left(\mathrm{r}^{2}=0.88-1.00, \mathrm{P}<0.0001\right)$. Inclusion of the $\mathrm{LO}$ at $50 \%$ of added dietary

9 lipid reduced flesh docosahexaenoic (22:6n-3; DHA) and eicosapentaenoic acids (20:5n-

103 ; EPA) to 65 and $58 \%$, respectively, of the concentrations in fish fed FO. When

11 inclusion of dietary LO reached 100\% the flesh DHA and EPA concentrations were

12 reduced to 38 and $30 \%$, respectively, of values in fish fed FO. Differences between diet

13 fatty acid concentration and flesh fatty acid concentration showed that 16:0, 18:1n-9 and

14 especially DHA were preferentially retained by salmon whereas $18: 2 n-6,18: 3 n-3$ and

$1522: 1 \mathrm{n}-11$ were selected against and presumably utilised for energy production. Feeding a

16 finishing diet containing FO alone for 16 weeks restored flesh DHA and EPA

17 concentrations in fish previously fed 50 and $100 \%$ LO to around $80 \%$ of their values in

18 fish fed FO throughout. Flesh DHA and EPA concentrations in fish fed up to 50\% LO

19 were in excess of recommended intake values for these fatty acids. By utilising FO

20 finishing diets for at least 16 weeks similar flesh DHA and EPA concentrations could be

21 achieved in fish previously fed up to $100 \%$ LO for 40 weeks. This study suggests that LO

22 can be used as a substitute for FO in salmon feeds during seawater growth and that any

23 reductions in DHA and EPA can be overcome by feeding FO for a period before harvest. 
1 The importance of the n-3 PUFA, and specifically the $n-3$ highly unsaturated fatty acids

2 (HUFA) docosahexaenoic (22:6n-3; DHA) and eicosapentaenoic acids (20:5n-3, EPA) in

3 human nutrition, is now widely recognised $(1,2)$. There is also increasing evidence that a

4 range of conditions currently prevalent in the developed world, including cardiovascular

5 disease, diabetes, rheumatoid arthritis, neurological disorders and the metabolic

6 syndrome, are influenced by changes in dietary fatty acid intake (3).

7 Fish, particularly those with high levels of body oil, like salmon, herring and sardines,

8 represent a rich source of EPA and DHA for the human consumer. Due to increased

9 population pressure worldwide demand for seafood is increasing yet traditional food-

10 grade fisheries are unable to match demand with supply (4). Increased demand has

11 resulted in rapid expansion of aquaculture production to alleviate this potential seafood

12 deficit $(5,6)$. However, the feed-grade fisheries that have supplied the raw materials for

13 aquaculture feeds have reached sustainable limits and it is estimated that by $2010>85 \%$

14 of world fish oil supplies will be used for aquaculture production (7). Consequently,

15 continued expansion of the aquaculture industry can only occur if sustainable alternatives

16 to fish oil (FO), derived from terrestrial plants, are researched and implemented.

17 The lipids in feeds for Atlantic salmon must meet both energy and EFA requirements to

18 allow the rapid growth and development required in modern aquaculture production $(8,9)$.

19 Earlier studies on $\beta$-oxidation activity suggest that salmonid fish have a preference for

$20 \quad 16: 0,16: 1,18: 1 \mathrm{n}-9$ and $22: 1 \mathrm{n}-11$ as well as $18: 2 \mathrm{n}-6(10,11)$ although more recent studies

21 with salmon suggest that 18:3n-3 and 20:5n-3 may also be utilised for energy production

22 when present at higher concentrations (12-14). The high latitude FO, that are currently

23 favoured in salmon production, are very rich in 20:1n-9 and 22:1n-11 while different 
1 vegetable oils are rich in 16:0, 18:1n-9, 18:2n-6 and 18:3n-3. Several recent studies have

2 shown that salmon can be cultured for up to 30 weeks using diets formulated with up to

$3100 \%$ replacement of added $\mathrm{FO}$ by vegetable oils (15-18). The ability to convert $\mathrm{C}_{18}$

4 PUFA to their long chain HUFA products has been confirmed in Atlantic salmon as has

5 the up-regulation of these pathways in hepatocytes and enterocytes of fish fed vegetable

6 oil-containing diets $(19,20)$. However, the increased flux through the fatty acid

7 desaturation and elongation pathway is unlikely to compensate fully for reduced dietary

8 EPA, DHA and possibly arachidonic acid requirements and, thus, sufficient dietary

9 supply of these HUFA will need to be provided $(12,13)$.

10 Atlantic salmon fed diets containing raw materials of predominantly marine origin are

11 of high nutritional quality being rich in EPA and DHA and with an n-3/n-6 ratio of

12 around 4:1 $(21,22)$. Recent studies have shown that salmon cultured using diets where >

$1350 \%$ of added FO has been replaced with vegetable oil show significant reductions in

14 flesh EPA and DHA concentrations (14-17). Obviously, from a human health

15 perspective, any changes to n-3 HUFA content should be kept to a minimum and any FO

16 replacement should provide sufficient energy alternatives to long-chain monoenes,

17 maximise conversion of dietary 18:3n-3 and preserve endogenous n-3 HUFA levels. In

18 this regard linseed oil is an important candidate for FO replacement, not only because it is

19 rich in 18:3n-3, the precursor for n-3 HUFA but, 18:3n-3 is also a favoured substrate for

$20 \beta$-oxidation both in salmonid fish and in mammals $(12-14,23)$. Furthermore, increasing

21 salmon flesh concentrations of 18:3n-3 should not be perceived as detrimental, from a

22 human nutrition perspective, as $18: 3 \mathrm{n}-3$ has been shown to be beneficial in cardiovascular 
1 disease and some forms of cancer (24), possibly due to inhibition of 18:2n-6 conversion

2 to $20: 4 n-6$ and inhibition of cyclooxygenase $(25,26)$.

3 In the present study, Atlantic salmon post-smolts were stocked into 5 seawater pens one

4 of four diets containing $25,50,75$ or $100 \%$ LO, or a control diet containing only FO. The

5 fish were grown for 40 weeks before sampling and thereafter all treatments were

6 switched to a diet containing only FO for a further 24 weeks to follow accumulation of

7 DHA and EPA and dilution of 18:3n-3 and 18:2n-6 from LO.

8

9 MATERIALS AND METHODS

$10 \quad$ Fish and diets

11 Atlantic salmon post-smolts $(\mathrm{n}=3000)$ of initial mean weight $127 \pm 3 \mathrm{~g}$ (individual

12 weights of 50 fish/pen) were distributed into five net pens ( 5 x 5m; 600 fish/pen) in Loch

13 Duich, Lochalsh, Scotland, in June 2001. The temperature over the experimental period

14 (June 2001-December 2002) ranged from $5.0-16.8^{\circ} \mathrm{C}$ with a mean temperature of $10.8 \pm$

$152.2^{\circ} \mathrm{C}$. The fish were fed one of four experimental diets in which the $\mathrm{FO}$ component was

16 replaced by LO or a control diet containing only FO (capelin oil). Specifically the five

17 diets were 100\% FO (FO), FO/LO, 3:1 w/w (25\% LO); FO/LO, 1:1 w/w (50\% LO);

$18 \mathrm{FO} / \mathrm{LO}, 1: 3 \mathrm{w} / \mathrm{w}(75 \% \mathrm{LO})$ and $100 \% \mathrm{LO}$. Feeds were fed to satiation by hand for a

19 period of 40 weeks and all feed fed was recorded. After this time samples of fish were

20 collected for analysis and the remaining fish were all switched to the FO diet for a further

2124 weeks. The 5 practical type diets were formulated (Nutreco Aquaculture Research

22 Centre, Stavanger, Norway) to fully satisfy the nutritional requirements of salmonid fish

23 and differed only in their oil composition (27). The main dietary components were 
1 fishmeal, $338 \mathrm{~g} \mathrm{~kg}^{-1}$, capelin oil $0-258 \mathrm{~g} \mathrm{~kg}^{-1}$ and/or linseed oil $0-258 \mathrm{~g} \mathrm{~kg}^{-1}$, maize gluten

$2200 \mathrm{~g} \mathrm{~kg}^{-1}$, soya meal $100 \mathrm{~g} \mathrm{~kg}^{-1}$ and micronutrients $25 \mathrm{~g} \mathrm{~kg}^{-1}$. The diets were produced in 3 ,

36 and $9 \mathrm{~mm}$ sizes and had average proximate compositions of $44.1 \pm 0.3 \%$ crude protein,

$4 \quad 29.4 \pm 0.6 \%$ crude lipid, $7.1 \pm 0.45 \%$ ash and $5.9 \pm 0.3 \%$ moisture. The fatty acid

5 compositions of the experimental diets are shown in Table 1. The FO diet containing

6 capelin oil contained about $20 \%$ saturates, mainly 16:0 and almost $60 \%$ monoenes of

7 which 50\% were the long chain 20:1n-9 and 22:n-11. The FO diet contained 5\% n-6 fatty

8 acids, mostly 18:2n-6 and 16\% n-3 fatty acids, dominated by EPA and DHA in almost

9 equal amounts and with 18:3n-3 less than $1 \%$. Addition of increasing levels of dietary LO

10 resulted in increasing levels of $18: 3 n-3,18: 2 n-6$ and 18:1n-9 and decreasing levels of

11 EPA, DHA, 16:0, total saturates, 20:1n-9, 22:1n-11 and total monoenes. Thus, the $100 \%$

12 LO diet contained $10 \%$ total saturates, $21 \%$ total monoenes, $15 \% 18: 2 n-6,50 \% 18: 3 n-3$

13 with EPA and DHA accounting for only $2.5 \%$ of total dietary fatty acids.

\section{Sampling procedures}

15 After 40 weeks, 18 fish were selected from each treatment and killed by a blow to the

16 head after anaesthetising using MS222 (Sigma-Aldrich, Poole, England). A sample of

17 flesh, representative of the edible portion was obtained by cutting a steak between the

18 leading and trailing edges of the dorsal fin. The samples were combined as six pools of 3

19 steaks in each pool. The steaks were frozen on dry ice and stored at $-40^{\circ} \mathrm{C}$ until

20 processed. The steaks were thawed, skinned, deboned and the flesh homogenised in a

21 food processor, after removal of the dorsal fat body. The homogenate was frozen

22 immediately and stored at $-40^{\circ} \mathrm{C}$ prior to analysis. During the period where fish from all

23 treatments were returned to a FO diet samples were collected after 4, 8, 16 and 24 weeks 
1 following reintroduction of FO diets. At each time point nine fish were sampled from

2 each treatment group and were combined as three pools of 3 steaks in each pool. The

3 steaks were processed and stored as described above.

$4 \quad$ Lipid extraction and fatty acid analysis. Total lipid was extracted from $2 \mathrm{~g}$ of

5 homogenised muscle by homogenising in 20 volumes of chloroform/methanol $(2: 1, \mathrm{v} / \mathrm{v})$

6 in an Ultra-Turrax tissue disrupter (Fisher Scientific, Loughborough, U.K.). Total lipid

7 was prepared according to the method of Folch et al. (28) and non-lipid impurities

8 removed by washing with $0.88 \%(\mathrm{w} / \mathrm{v}) \mathrm{KCl}$. The weight of lipid was determined

9 gravimetrically after evaporation of solvent and overnight desiccation in vacuo. Fatty

10 acid methyl esters were prepared by acid-catalysed transesterification of total lipid

11 according to the method of Christie (29). Extraction and purification of fatty acid methyl

12 esters was performed as described by Ghioni et al. (30). Fatty acid methyl esters were

13 separated and quantified by gas-liquid chromatography (Carlo Erba Vega 8160, Milan,

14 Italy) using a 30m x $0.32 \mathrm{~mm}$ i.d. capillary column (CP Wax 52CB, Chrompak, London,

15 U.K.) and on-column injection. Hydrogen was used as carrier gas and temperature

16 programming was from $50^{\circ} \mathrm{C}$ to $150^{\circ} \mathrm{C}$ at $40^{\circ} \mathrm{C} \mathrm{min}^{-1}$ and then to $230^{\circ} \mathrm{C}$ at $2.0^{\circ} \mathrm{C} \mathrm{min}$.

17 Individual methyl esters were identified by comparison with known standards and by

18 reference to published data (30). Data were collected and processed using the Chromcard

19 for Windows (version 1.19) computer package (Thermoquest Italia S.p.A., Milan, Italy).

20 Statistical analysis. Significance of difference $(\mathrm{P}<0.05)$ between dietary treatments was

21 determined by one-way analysis of variance (ANOVA). Differences between means were

22 determined by Tukey's test. Data identified as non-homogeneous, using Bartlett's test,

23 were subjected to log or arcsin transformation before applying the ANOVA. ANOVA 
1 and regression analysis was performed using a Graphpad Prism ${ }^{\mathrm{TM}}$ (version 3.0) statistical

2 package (Graphpad Software, San Diego, CA).

4 RESULTS

5 After feeding the five diets for 40 weeks the final weights of the fish were $1.79 \pm 0.40 \mathrm{~kg}$

6 (FO), $1.89 \pm 0.34 \mathrm{~kg}(25 \% \mathrm{LO}), 1.9 \pm 0.33 \mathrm{~kg}(50 \% \mathrm{LO}), 1.87 \pm 0.35 \mathrm{~kg}(75 \% \mathrm{LO})$ and

$7 \quad 1.87 \pm 0.33 \mathrm{~kg}(100 \% \mathrm{LO})$ and there were no significant differences between dietary

8 treatments $(\mathrm{P}=0.156, \mathrm{n}=87)$. Specific growth rates were very similar (\% weight gain

9 day $\left.^{-1}\right)$ varying from $0.94(\mathrm{FO})$ to $0.98(25 \% \mathrm{LO})$ and feed conversion ratios (dry feed

10 consumed/wet weight gain) varied from $1.29(25 \& 75 \% \mathrm{LO})$ to $1.41(50 \% \mathrm{LO})$. Flesh

11 lipid content varied from $7.4 \pm 1.4 \%$ (FO) to $8.8 \pm 1.7 \%(25 \% \mathrm{LO})$ and flesh astaxanthin

12 content from $3.31 \pm 0.58 \mathrm{mg} \mathrm{kg}^{-1}$ (FO) to $3.60 \pm 0.49 \mathrm{mg} \mathrm{kg}^{-1}$ (50\% LO). These values

13 showed no significant differences between dietary treatments.

14 Flesh fatty acid compositions; 40 weeks feeding LO-containing diets The fatty acid

15 compositions of flesh total lipid reflected the changes in dietary fatty acids due to

16 increasing inclusion of LO (Table 2). Total saturated fatty acids decreased significantly

17 with increasing LO inclusion, largely due to significant reductions in both 14:0 and 16:0,

18 although 18:0 was increased with addition of LO. Total monoene fatty acids were

19 reduced by more than half in fish fed $100 \%$ LO compared to those fed FO due to

20 significant reductions in 16:1n-7, 20:1n-9 and 22:1n-11 with each addition of dietary LO.

21 Total n-6 fatty acids were increased by more than 2-fold, largely due to $18: 2 n-6$

22 increasing from $3.9 \mathrm{~g} / 100 \mathrm{~g}$ in flesh from FO fish to $13.1 \mathrm{~g} / 100 \mathrm{~g}$ in fish fed $100 \% \mathrm{FO}$.

23 Flesh 20:4n-6 concentrations were significantly lower in fish fed 75 and 100\% LO 
1 compared to those fed FO. Total n-3 fatty acids were increased significantly with each

2 addition of LO, largely due to increased flesh deposition of 18:3n-3, although the

3 elongation and desaturation products, $20: 3 n-3$ and 20:4n-3 were also increased

4 significantly. However, both EPA and DHA were significantly reduced in flesh from fish

5 fed LO with values for EPA and DHA in fish fed 100\% LO being reduced to 30 and $38 \%$

6 of values in fish fed FO. The n-3/n-6 ratios were similar for all treatments being in the

7 range of 3.2-3.6.

$8 \quad$ Plotting fatty acid concentration $(\mathrm{g} / 100 \mathrm{~g})$ in flesh lipid (Table 2 ) against fatty acid

9 concentration in dietary lipid (Table1) resulted in straight line graphs and some examples

10 are shown in Figs. 1 and 2. These graphs demonstrate that concentrations of dietary fatty

11 acids were linearly correlated with flesh fatty acid concentrations, with $r^{2}$ values in the

12 range $0.966-0.999$, and that different slope values indicate that the relationship between

13 dietary and flesh fatty acid concentrations is different for each fatty acid (Table 3 ). This is

14 shown more clearly in Table 3 by comparing the differences ( $\Delta$ values) between the

15 concentration of individual fatty acids in dietary lipid and flesh lipid for fish fed the FO,

$1650 \% \mathrm{LO}$ and $100 \% \mathrm{LO}$. This shows that, for all the PUFA and HUFA listed in Table 3,

17 only DHA was present in flesh at a greater concentration than that in the diet for all three

18 treatments. This situation is in contrast with both 18:3n-3, which was always present in

19 flesh at a lower concentration than in diets, and 20:5n-3 which only had a higher value in

20 flesh compared to diet when diet concentrations were low. Interestingly, 16:0, total

21 saturates and 18:1n-9 all showed positive $\Delta$ values for each of the three diets suggesting

22 both saturated fatty acids and $18: 1 \mathrm{n}-9$ were being preferentially retained by the fish. In

23 contrast, $18: 2 \mathrm{n}-6,18: 3 \mathrm{n}-3,20: 1 \mathrm{n}-9$ and $22: 1 \mathrm{n}-11$ were generally discriminated against in 
1 terms of flesh deposition particularly when present at high concentrations in the diet. This

2 suggests that these four fatty acids, in comparison to the saturates or 18:1n-9, were

3 selectively utilised for metabolism, probably for energy production.

4 Flesh fatty acid compositions; 24 weeks refeeding FO-containing diets to all dietary

5 treatments By returning all experimental treatments to a FO-containing diet for 24 weeks,

6 following the initial 40 week feeding phase, the differences between flesh fatty acid

7 compositions were reduced (Table 4). The concentrations of 16:0 and total saturates were

8 only significantly higher in fish fed FO throughout compared to those previously fed 75

9 and $100 \%$ LO. A similar result was seen for $16: 1 \mathrm{n}-7$ while $20: 1 \mathrm{n}-9$ and $22: 1 \mathrm{n}-11$ were

10 still significantly different for all treatment groups except that fish previously fed $75 \%$

11 LO were not different from those fed 50 or $100 \%$ LO. Concentrations of total monoenes

12 showed similar differences but the concentration in fish previously fed $100 \% \mathrm{LO}$ was

13 restored to $80 \%$ of the value in fish fed FO throughout. The $18: 2 n-6$ and total $n-6$ fatty

14 acid concentrations were not different between fish fed either FO or $25 \% \mathrm{LO}$ and these

15 two treatments were significantly lower than fish previously fed 75 and 100\% LO.

16 Concentrations of flesh 20:4n-6 were restored to similar values for all dietary treatments.

17 The flesh concentrations of 18:3n-3 were significantly higher in fish previously fed 75

18 and $100 \%$ LO, compared to fish previously fed $50 \%$ or $25 \%$ LO or FO. The

19 concentration of EPA was significantly higher in fish fed FO throughout compared to

20 those previously fed 50,75 and 100\% LO while concentrations of 22:5n-3 were

21 significantly higher in fish fed FO throughout compared to all other treatments, which has

22 similar concentrations. The concentration of flesh DHA was significantly higher in fish

23 fed FO throughout compared to fish previously fed 50 and 100\% LO. Concentrations of 
1 total n-3 fatty acids were significantly higher in fish previously fed 75 and 100\% LO

2 compared to fish fed the other three diets.

3 After feeding the experimental diets for 40 weeks the flesh18:2n-6 concentration was

4 significantly different between fish fed FO, 50\% LO and 100\% LO (Fig. 3A) with the

5 highest values in fish fed 100\% LO being 236\% higher than in fish fed FO. After feeding

6 the FO-containing finishing diet to all treatments the 18:2n-6 concentrations were still

7 significantly different between the treatments after 56 and 64 weeks. However, after 64

8 weeks the 18:2n-6 concentrations in fish previously fed the 50\% and 100\% LO diets had

9 reduced by $31 \%$ and $44 \%$, respectively, following the 24 week FO refeeding period (Fig.

$103 \mathrm{~A}$ ). A similar result was observed for 18:3n-3 such that the concentrations of in fish

11 previously fed the 50 and $100 \%$ LO diets were still significantly different, both from each

12 other and, from fish fed FO after 16 and 24 weeks on a FO diet (Fig. 3B). However, the

13 concentrations of $18: 3 \mathrm{n}-3$, in fish previously fed $50 \%$ and $100 \%$ LO, had reduced by $64 \%$

14 and $66 \%$, respectively, following 24 week FO refeeding period.

15 After the initial 40 week feeding period the flesh concentration of EPA was

16 significantly lower in fish fed 50 and 100\% LO compared to those fed FO (Fig. 4A).

17 After refeeding FO for 16 and 24 weeks, the flesh EPA concentration increased such that

18 fish previously fed the 50 and 100\% LO diets had similar EPA concentrations but they

19 were still significantly lower than fish fed FO throughout. However, the flesh

20 concentrations of EPA, in fish previously fed $50 \%$ and $100 \%$ LO, were restored to $88 \%$

21 and 83\%, respectively, of the concentration in fish fed FO throughout, following the 24

22 week FO refeeding period. A very similar result was seen with flesh DHA concentrations

23 in fish previously fed 50\% and 100\% LO whereby DHA concentrations were restored to 
$180 \%$ and $83 \%$, respectively, of the concentration in fish fed FO throughout, following the

224 week refeeding period. Interestingly, the flesh EPA and DHA concentrations were

3 restored to 81 and $74 \%$ and 85 and $79 \%$, respectively, for fish previously fed $50 \%$ and

$4100 \%$ LO diets, respectively, following refeeding the FO diet for only 16 weeks.

\section{DISCUSSION}

7 Salmon produced using diets containing raw materials with high levels of marine fish oils

8 currently provide a rich source of the n-3 HUFA, EPA and DHA, that are relatively cheap

9 and highly nutritious $(21,22)$. However, the growth in aquaculture required to augment

10 dwindling seafood stocks can only be sustained if alternatives to marine fish oils (FO)

11 can be found $(5,7)$. In the present study graded levels of linseed oil were used to replace

12 FO in the culture of Atlantic salmon to market size with no obvious detriment in terms of

13 growth and health of the fish. Although a number of previous studies have looked at FO

14 substitution in salmon most have used smaller fish or that were grown on the

15 experimental feeds for relatively short periods $(16,17,32,33,34)$. However, the growth

16 results obtained with the present study using LO compare favourably with studies

17 utilising soya and rapeseed oils as FO replacements and suggests that the energy

18 requirements of Atlantic salmon can be satisfied by vegetable oils with variable fatty acid

19 compositions $(18,35)$. A few studies have investigated LO alone, or blended with other

20 oils, in salmon feeds and these have also confirmed no obvious effects on growth

21 parameters $(14,33,34)$.

22 Atlantic salmon store high amounts of lipid in their flesh and in market size salmon (2-

$235 \mathrm{~kg})$ lipid levels would normally be in the range of $10-20 \%$ of wet weight $(21,22)$. 
1 Changing the fatty acid composition of salmon diets can affect the composition and

2 quantity of flesh lipid stores and previous studies using rapeseed and palm oils, to replace

3 FO, observed reduced flesh lipid at replacement levels above $50 \%(16,17)$. In the present

4 study, fish of $\sim 2 \mathrm{~kg}$ had lipid levels of 7.4-8.8\% and there were no significant differences

5 between treatments. In a previous study with salmon harvested at a similar size, and fed

6 diets with varying levels of FO, LO and rapeseed oil, no differences in flesh lipid content

7 were observed (14). However, lipid concentrations in the liver of fish from the present

8 dietary trial showed significantly increased lipid deposition in fish fed diets with $>50 \%$

9 LO, suggesting that changes in diet fatty acid composition can affect adiposity in specific

10 tissues (19).

11 It is well documented that tissue fatty acid compositions in salmonid fish are closely

12 related to dietary fatty acid compositions and that feeding high levels of vegetable oils

13 will strongly influence flesh fatty acid compositions (14-18). The results from the present

14 study confirm this relationship in which linear correlations between dietary fatty acid

15 concentrations and flesh fatty acid concentrations are clearly demonstrated. In previous

16 studies similar linear relationships have been observed where rapeseed, palm and blends

17 of rapeseed and linseed oil were used, along with FO, in salmon feed formulations

$18(14,16,17)$. The present study has confirmed that individual fatty acids, within a blend of

19 dietary fatty acids, are selectively retained or metabolised depending on their

20 concentration in the diet and the biological function of the specific fatty acids. In practical

21 terms, these linear correlations (Figs. 1 \& 2) can be used to predict the flesh concentration

22 of a particular fatty acid when present in a mixture of fatty acids, derived from blends of

$23 \mathrm{LO}$ and $\mathrm{FO}$, fed to salmon in sea water. 
1 Additional information on selective retention or metabolism of different dietary fatty

2 acids, present in different oil blends, can be obtained from Figs $1 \& 2$ and in Tables $2 \&$

35 . One of the most striking effects is the preferential deposition and retention of DHA in

4 flesh lipids, regardless of concentration present in the diet. The $\Delta$ values in Table 5 show

5 positive values in the range 1.6-3.1 for $100 \% \mathrm{LO}, 50 \% \mathrm{LO}$ and $\mathrm{FO}$ treatments indicating

6 that, regardless of dietary concentration, DHA was selectively deposited and retained in

7 salmon flesh. This selectivity presumably reflects the specificity of the fatty acyl

8 transferase enzymes that perform the incorporation of fatty acids into flesh TAG and

9 phospholipids and has been observed in previous studies with salmon fed different

10 combinations of vegetable oils $(14,16,17)$.

11 By comparison, the other PUFA and HUFA tended to be directed towards metabolism,

12 presumably largely for energy production, rather than deposition, especially when present

13 at high concentrations. When present at low concentrations only EPA showed a positive

$14 \Delta$ value while both $18: 2 n-6$ and especially $18: 3 n-3$ were selected against in terms of flesh

15 deposition. The tendency towards preferential metabolism of $\mathrm{C}_{18}$ PUFA by $\beta$-oxidation

16 has been observed, not only in salmonid fish $(12,13)$, but also in humans where $18: 3 \mathrm{n}-3$

17 was preferred over 18:2n-6 as an oxidative substrate (23). However, it should also be

18 noted that both $18: 2 n-6$ and $18: 3 n-3$ are substrates for $\Delta 6$-desaturase and it has been

19 reported that Atlantic salmon hepatocytes tend to favour desaturation and elongation of

$2018: 3 n-3$ over 18:2n-6 (20,34). In addition to PUFA, the long-chain monoene fatty acids,

21 that are characteristic of high latitude fish oils (9), are thought to be important catabolic

22 substrates. This appeared to be confirmed in the present study where the preference 
1 appeared to be for $22: 1 \mathrm{n}-11$ over $20: 1 \mathrm{n}-9$ even though the former was less abundant in

2 the diets than the latter.

3 The literature suggests that $22: 1 \mathrm{n}-11$ and $18: 2 \mathrm{n}-6$ are preferred substrates for $\beta$ -

4 oxidation, along with 16:0, 16:1 and 18:1n-9 $(11,36,37)$. However, in the present study

$5 \quad$ 16:0, and especially 18:1n-9, had positive $\Delta$ values (Table 5) indicating that these two

6 fatty acids were being selectively retained in flesh lipids rather than being metabolised for

7 energy production. This is in contrast to two previous studies which showed that $18: 1 \mathrm{n}-9$

8 was used for energy production by the $\beta$-oxidation pathway in salmon fed diets

9 containing blends of LO and rapeseed oil although both 18:2n-6 and 18:3n-3 appeared to

10 be preferred over 18:1n-9 $(14,35)$. Perhaps these differences can be explained in part by

11 genetic differences in salmon stocks utilised in the different trials. The selection of $18: 1 \mathrm{n}$ -

129 and 16:0 for deposition, rather than mobilisation, in flesh may reflect the structural

13 function of these fatty acids in membrane phospholipids where they are often located in

14 the $s n-1$ position of phospholipids, especially of PC and PE, with HUFA being favoured

15 in the $s n-2$ position $(9,38)$.

16 The diet of early humans pursuing a hunter/gatherer lifestyle was probably

17 considerably lower in fat and had an $n-6 / n-3$ ratio of around 1:1 in comparison to the

18 current diet in the developed world with an n-6/n-3 ratio of 10-20:1 (39). The health

19 benefits of diets rich in EPA and DHA, that can reduce this high n-6/n-3 ratio, are well

20 documented and the outcome of a number of conditions prevalent in the developed world,

21 including cardiovascular disease, immune dysfunction, diabetes and other inflammatory

22 disorders, can be improved as a result (40-42). While outcomes of clinical trials with

23 18:3n-3 have been less clear than with n-3 HUFA there is evidence that diets promoting 
1 increased tissue levels of 18:3n-3 can also be beneficial to health (24). Benefits of

2 increased 18:3n-3 for cardiovascular disorders, including rhythm disorders, myocardial

3 infarctions, sudden cardiac death and coronary thrombosis have been reported (43-45). In

4 addition, some studies have reported low tissue levels of ARA as risk factors for both

5 breast and prostate cancers $(46,47)$.

6 Atlantic salmon presently cultured using only marine fish oils are rich in n-3 HUFA and

7 as such represent a valuable source of EPA and DHA for the human consumer $(21,22)$.

8 The present study suggests that salmon cultured with LO replacing up to $50 \%$ of FO

9 results in moderate reduction of n-3 HUFA, but increased deposition of 18:3n-3, and only

10 moderate deposition of 18:2n-6, means that flesh n-3/n-6 ratios of $>3$ are maintained.

11 Furthermore, even salmon fed 100\% LO provide n-3 HUFA levels of 0.12g EPA and

$120.28 \mathrm{~g}$ DHA, as well as $3.48 \mathrm{~g} 18: 3 \mathrm{n}-3$ and $1.12 \mathrm{~g} 18: 2 \mathrm{n}-6$, per $100 \mathrm{~g}$ of salmon flesh. These

13 values are close to the recommended $0.22 \mathrm{~g} /$ day each for EPA and DHA, 2.22g/day for

$1418: 3 \mathrm{n}-3$, and are well below the maximum recommended 18:2n-6 intake of $6.67 \mathrm{~g} /$ day

15 (39). However, it is also recommended to increase the dietary n-3/n-6 ratio and especially

16 to increase n-3 HUFA of marine origin $(39,40)$.

17 This study has demonstrated mechanisms by which the ratio of DHA/EPA/18:3n-

$183 / 18: 2 \mathrm{n}-6$ can be manipulated in salmon flesh so that precise "tailored" EFA

19 compositions can be delivered to human consumers. This can be achieved via the initial

20 dietary input, for the majority of the ongrowing phase, and by the use of a FO finishing

21 diet to restore the values of the aforementioned EFA to the desired concentrations. The

22 latter procedure restored both EPA and DHA concentrations in flesh to $>80 \%$ of the

23 value in fish fed FO throughout after 24 weeks while $18: 2 n-6$ and $18: 3 n-3$ concentrations 
1 were $74 \%$ and 13 -fold higher than in fish fed FO. These results are similar to previous

2 studies with Atlantic salmon and gilthead seabream which showed that restoration of

3 flesh EPA and DHA concentrations can be achieved relatively easily with finishing diets

4 but that $\mathrm{C}_{18}$ PUFA concentrations still remain elevated $(14,48)$.

5 In conclusion, this study suggests that Atlantic salmon can be cultured, during the

6 marine phase of their life cycle, using diets in which the FO is replaced by LO without

7 apparent reduction in growth rates or fish health. In addition, this study has shown that

8 salmon cultured with diets containing up to $50 \%$ LO, or up to $100 \%$ LO followed by a

9 period of 16-24 weeks on a FO finishing diet, can provide a carcass EFA composition

10 that is highly beneficial for human health. While the goal of minimising reliance on

11 marine raw materials cannot be achieved overnight this study suggests that salmon can be

12 cultured on diets with minimal FO input yet still retain a high functional nutritional value

13 that cannot be replicated in terrestrial farmed foodstuffs.

\section{ACKNOWLEDGEMENT}

16 This work was supported by the European Union Framework V programme (Researching

17 alternatives to fish oils in aquaculture, RAFOA, QLRT-2000-30058). We would like to

18 acknowledge Mr Bill Gordon and Mr Iain Martin for their assistance with fish husbandry.

\section{REFERENCES}

20 1. Simopoulos, A.P. (1999) Essential fatty acids in health and chronic disease. Am. J.

$21 \quad$ Nutr. 70, 560S-569S.

22 2. Connor, W.E. (2000) Importance of n-3 fatty acids in health and disease. Am. J. Clin.

$23 \quad$ Nutr. 71, 171S-175S. 
13 . WHO report (2002) Reducing risks, promoting a healthy life. World Health

2 Organisation, Geneva, Switzerland. ISBN 924156207 0: ISSN 1020-3311.

3 4. Williams, N. (1998). Overfishing disrupts entire ecosystems. Science 279, 809-810.

4 5. Tidwell, J.H., and Allan, G.L. (2002). Fish as food: aquaculture's contribution. World $5 \quad$ Aquaculture 33, 44-48.

6 6. Sargent, J.R., and Tacon, A.G.J. (1999) Development of farmed fish: a nutritionally

7 necessary alternative to meat. Proc. Nutr. Soc. 58, 377-383.

8 7. Barlow, S. (2000). Fishmeal and fish oil: sustainable ingredients for aquafeeds. Glob. $9 \quad$ Aquacult. Advocate 4, 85-88.

10 8. Frøyland, L., Madsen, L., Eckhoff, K.M., Lie, Ø., and Berge, R. (1998). Carnitine

11 palmitoyltransferase I, carnitine palmitoyltransferase II, and acyl-CoA oxidase 12 activities in Atlantic salmon (Salmo salar) Lipids, 33, 923-930.

13 9. Sargent, J.R., Tocher, D.R., and Bell, J.G. (2002). The Lipids, in Fish Nutrition, Third

14 Edition. (Halver, J.E., and Hardy, R.W. eds.) pp. 181-257. Elsevier Science (USA).

15 10. Henderson, R.J., and Sargent, J.R. (1985). Chain length specificities of mitochondrial

16 and peroxisomal $\beta$-oxidation of fatty acids in rainbow trout (Salmo gairdneri).

17 Comp. Biochem. Physiol. 82B, 79-85.

18 11. Henderson, R.J. (1996). Fatty acid metabolism in freshwater fish with particular

19 reference to polyunsaturated fatty acids. Arch. Anim. Nutr. 49, 5-22.

20 12. Bell, M.V., Dick, J.R., and Porter, A.E.A. (2001) Biosynthesis and tissue deposition

21 of docosahexaenoic acid (22:6n-3) in rainbow trout (Oncorhynchus mykiss) Lipids

$22 \quad 36,1153-1159$. 
1 13. Bell, M.V., Dick, J.R., and Porter, A.E.A. (2003) Pyloric ceca are a major site of

2 22:6n-3 synthesis in rainbow trout (Oncorhynchus mykiss). Lipids 39, 39-44.

3 14. Bell, J.G., Tocher, D.R., Henderson, R.J., Dick, J.R., and Crampton, V.O. (2003)

$4 \quad$ Altered fatty acid compositions in Atlantic salmon (Salmo salar) fed diets containing

$5 \quad$ linseed and rapeseed oils can be partially restored by a subsequent fish oil finishing

6 diet. J. Nutr. 133, 2793-2801.

7 15. Torstensen, B.E., Lie, O., and Froyland, L. (2000). Lipid metabolism and tissue

8 composition in Atlantic salmon (Salmo salar L.) - effects of capelin oil, palm oil and

9 oleic acid - enriched sunflower oil as dietary lipid sources. Lipids, 35, 653-664.

10 16. Bell, J.G., McEvoy, J., Tocher, D.R., McGhee, F., Campbell, P.J., and Sargent, J.R.

11 (2001) Replacement of fish oil with rapeseed oil in diets of Atlantic salmon (Salmo

12 salar) affects tissue lipid compositions and hepatocyte fatty acid metabolism. J. Nutr.

$13 \quad 131,1535-1543$.

14 17. Bell, J.G., Henderson, R.J., Tocher, D.R., McGhee, F., Dick, J.R., Porter, A.,

15 Smullen, R.P., and Sargent, J.R. (2002) Substituting fish oil with crude palm oil in

16 the diet of Atlantic salmon (Salmo salar) affects muscle fatty acid composition and

17 hepatic fatty acid metabolism. J. Nutr.132, 222-230.

18 18. Rosenlund, G., Obach, A., Sandberg, M.G., Standal, H., and Tveit, K. (2001). Effect

19 of alternative lipid sources on long-term growth performance and quality of Atlantic

20 salmon (Salmo salar L.) Aqua. Res. 32, 323-328.

21 19. Tocher, D.R., Fonseca-Madrigal, J., Bell, J.G., Dick, J.R., Henderson, R.J., and

22 Sargent, J.R. (2002) Effects of diets containing linseed oil on fatty acid desaturation 
and oxidation in hepatocytes and intestinal enterocytes in Atlantic salmon (Salmo salar) Fish Physiol. Biochem. 26, 157-170.

3 20. Ruyter, B., Røsjø, C., Grisdale-Helland, B., Rosenlund, G., Obach, A., and

4 Thomassen, M.S. (2003) Influence of temperature and high dietary linoleic acid

5 content on esterification, elongation, and desaturation of PUFA in Atlantic salmon

6 hepatocytes. Lipids 38, 833-840.

7 21. Bell, J.G., McEvoy, J., Webster, J.L., McGhee, F., Millar, R.M., and Sargent, J.R.

8 (1998) Flesh lipid and carotenoid composition of Scottish farmed Atlantic salmon

9 (Salmo salar). J.Agric. Food Chem. 46, 119-127.

10 22. Aursand, M., Mabon, F., and Martin, G.J. (2000) Characterization of farmed and wild

11 salmon (Salmo salar) by a combined use of compositional and isotopic analyses.

12 J.A.O.C.S. 77, 659-666.

13 23. DeLany, J.P., Windhauser, M.M., Champagne, C.M., and Bray, G.A. (2000)

14 Differential oxidation of individual dietary fatty acids in humans. Am. J. Clin. Nutr.

$15 \quad 79,905-911$.

16 24. Sinclair, A.J., Attar-Bashi, N.M., and Li, D. (2002) What is the role of $\alpha$-linolenic

17 acid for mammals? Lipids 37, 1113-1123.

18 25. Garg, M.L., Thomson, A.B.R., and Clandinin, M.T. (1990) Interactions of saturated,

19 n-6 and n-3 polyunsaturated fatty acids to modulate arachidonic acid metabolism. $J$.

$20 \quad$ Lipid Res. 31, 271-277.

21 26. Huang, Y.S., Smith, R.S., Redden, P.R., Cantrill, R.C., and Horrobin, D.F. (1991)

22 Modification of liver fatty acid metabolism in mice by n-3 and n- $6 \Delta 6$-desaturase

23 substrates and products. Biochim. Biophys. Acta 1082, 319-327. 
1 27. National Research Council (1993). Nutrient Requirements of Fish. National Academy

2 Press, Washington DC. ISBN 0-309-04891-5.

3 28. Folch, J., Lees, M., and Sloane-Stanley, G.H. (1957). A simple method for the

4 isolation and purification of total lipids from animal tissues. J. Biol. Chem. 226, 497-

5509.

6 29. Christie, W.W. (1982) Lipid Analyses, $2^{\text {nd }}$ ed., pp. 52-56. Pergamon Press, Oxford, $7 \quad$ England.

8 30. Ghioni, C., Bell, J.G., and Sargent, J.R. (1996) Polyunsaturated fatty acids in neutral

9 lipids and phospholipids of some freshwater insects. Comp. Biochem. Physiol. 114B, $10 \quad 161-170$.

11 31. Ackman, R.G. (1980) Fish lipids, part 1, in Advances in Fish Sciences and 12 Technology (Connell, J.J. ed.), pp. 86-103. Fishing News Books Ltd., Farnham, U.K.

13 32. Dosanjh, B.S., Higgs, D.A., McKenzie, D.J., Randall, D.J., Eales, J.G., Rowshandeli, 14 N., Rowshandeli, M., and Deacon, G. (1998) Influence of dietary blends of menhaden 15 oil and canola oil on growth, muscle lipid composition, and thyroidal status of Atlantic 16 salmon (Salmo salar) in sea water. Fish Physiol. Biochem. 19, 123-134.

17 33. Tocher, D.R., Bell, J.G., Dick, J.R., Henderson, R.J., McGhee, F., Mitchell, D.F., and 18 Morris, P.C. (2000) Polyunsaturated fatty acid metabolism in Atlantic salmon (Salmo 19 salar) undergoing parr-smolt transformation and the effects of dietary linseed and 20 rapeseed oils. Fish Physiol. Biochem. 23, 59-73.

21 34. Bell, J.G., Tocher, D.R., Farndale, B.M., Cox, D.I., McKinney, R.W., and Sargent, 22 J.R. (1997) The effect of dietary lipid on polyunsaturated fatty acid metabolism in 
Atlantic salmon (Salmo salar) undergoing parr-smolt transformation. Lipids 32, 515525.

3 35. Torstensen, B.E., Frøyland, L., and Lie, Ø. (2003) Replacing dietary fish oil with

4 increasing levels of rapeseed oil and olive oil- Effects on Atlantic salmon (Salmo

5 salar L.) tissue and lipoprotein lipid composition and lipogenic enzyme activities.

6 Aquac. Nutr. "in press".

7 36. Kiessling, K-H., and Keissling, A. (1993) Selective utilisation of fatty acids in

8 rainbow trout (Oncorhynchus mykiss Walbaum) red muscle mitochondria. Can.J.

$9 \quad$ Zool. 71, 248-251.

10 37. Frøyland, L., Lie, Ø., and Berge, R.K. (2000) Mitochondrial and peroxisomal beta-

11 oxidation capacities in various tissues from Atlantic salmon, Salmo salar. Aquac.

$12 \quad$ Nutr. 6, 85-89.

13 38. Bell, M.V., and Dick, J.R. (1991) Molecular species composition of the major diacyl

14 glycerophospholipids from muscle, liver, retina and brain of cod (Gadus morhua).

15 Lipids 26, 565-573.

16 39. Simopoulos, A.P. (2001) n-3 fatty acids and human health: defining strategies for

17 public policy. Lipids 36, S83-89.

18 40. De Deckere, E.A.M., Korver, O., Verschuren, P.M., and Katan, M.B. 1998. Health

19 aspects of fish and n-3 polyunsaturated fatty acids from plant and marine origin. Eur.

20 J. Clin. Nutr. 52, 749-753.

21 41. Bechoua, S., Dubois, M., Vericel, E., Chapuy, P., Lagarde, M., and Prigent, A.-F.

22 (2003) Influence of very low dietary intake of marine oil on some functional aspects

23 of immune cells in healthy elderly people. Br. J. Nutr. 89, 523-531. 
1 42. Sanderson, P., Finnegan, Y.E., Williams, C.M., Calder, P.C., Burdge, G.C., Wootton,

2 S.A., Griffin, B.A., Millward, D.J., Pegge, N.C., and Bemelmans, W.J.E. (2002) UK

3 Food Standards Agency alpha-linolenic acid workshop report. Br. J. Nutr. 88, 573-

4579.

5 43. Billman, G.E., Kang, J.X., and Leaf, A. (1999) Prevention of sudden cardiac death by

6 dietary pure omega-3 polyunsaturated fatty acids in dogs. Circulation 99, 2452-2457.

7 44. Singh, R.B., Niaz, M.A., Sharma, J.P., Kumar, R., Rastogi, V., and Moshiri, M.

8 (1997) Randomized double-blind, placebo-controlled trial of marine omega-3 oil and

9 mustard oil in patients with suspected acute myocardial infarction: The Indian

10 experiment of infarct survival-4. Cardiovasc. Drugs Therap. 11, 485-491.

11 45. Ferreti, A., and Flanagan, V.P. (1996) Antithromboxane activity of dietary $\alpha$ -

12 linolenic acid: A pilot study. Prostaglandins Leukot. Essent. Fatty Acids 54, 451-

13455.

14 46. Maillard, V., Bougnoux, P., Ferrari, P., Jourdain, M.L., Pinault, M., Lavillonniere, F.,

15 Body, G., Le Folch, O., and Chajes, V. (2002) n-3 and n-6 fatty acids in breast

16 cancer in case-control study in Tours, France. Int. J. Cancer 98, 78-93.

17 47. Newcomer, L.M., King, I.B., Wicklund, K.G., and Stanford, J.L. (2001) The

18 association of fatty acids with prostrate cancer. The Prostrate 47, 262-268.

21 48. Mourente, G., Good, J.E., and Bell, J.G. (2004) Partial substitution of fish oil with

22 rapeseed oil, linseed oil and olive oil in diets for European sea bass (Dicentrarchus

23 labrax $\mathrm{L}$.): effects on flesh fatty acid composition, plasma prostaglandins $\mathrm{E}_{2}$ and $\mathrm{F}_{2 a}$ 
1 production, and effectiveness of subsequent fish oil "wash out". Aquaculuture "in 2 press".

21 Figure legends.

22 FIG. 1. Relationship between dietary fatty acid concentration and muscle fatty acid

23 concentration for 22:6n-3 (A), 20:5n-3 (B) and 18:3n-3 (C) in total lipids of Atlantic 
1 salmon fed diets containing blends of fish oil (FO) and linseed oil (LO). The additional

2 line represents the line of equality.

3 FIG. 2. Relationship between dietary fatty acid concentration and muscle fatty acid

4 concentration for 18:2n-6 (A), 20:1n-9 (B) and 22:1n-11 (C) in total lipids of Atlantic

5 salmon fed diets containing blends of fish oil (FO) and linseed oil (LO). The additional

6 line represents the line of equality.

7 FIG. 3. Linoleic (18:2n-6) [A] and linolenic acid (18:3n-3) [B] concentration in total

8 lipid from salmon flesh after feeding diets containing $100 \%$ fish oil (FO), 50\% linseed oil

9 (50\% LO) or 100\% LO for 40 weeks and after feeding a 100\% FO diet for a further 16

10 and 24 weeks to all treatment groups. Columns assigned a different letter, within each

11 time point, are significantly different $(\mathrm{P}<0.05)$.

12 FIG. 4. Eicosapentaenoic (20:5n-3) [A] and docosahexaenoic acid (22:6n-3) [B]

13 concentration in total lipid from salmon flesh after feeding diets containing $100 \%$ fish oil

14 (FO), 50\% linseed oil (50\% LO) or 100\% LO for 40 weeks and after feeding a $100 \%$ FO

15 diet for a further 16 and 24 weeks to all treatment groups. Columns assigned a different

16 letter, within each time point, are significantly different $(\mathrm{P}<0.05)$. 
TABLE 1.

2 Fatty acid compositions (g/100g total fatty acids) and astaxanthin concentrations

$3 \quad(\mathrm{mg} / \mathrm{kg})$ in experimental diets.

\begin{tabular}{|c|c|c|c|c|c|}
\hline Fatty acid & FO & $25 \% \mathrm{LO}$ & $50 \% \mathrm{LO}$ & $75 \% \mathrm{LO}$ & $100 \% \mathrm{LO}$ \\
\hline$\overline{14: 0}$ & 6.3 & 4.7 & 3.4 & 2.0 & 0.4 \\
\hline $16: 0$ & 12.1 & 10.6 & 9.3 & 8.1 & 6.1 \\
\hline 18:0 & 1.1 & 1.7 & 2.1 & 2.7 & 3.1 \\
\hline Total saturates $^{1}$ & 19.9 & 17.2 & 15.1 & 13.0 & 10.5 \\
\hline $16: 1 n-7$ & 8.1 & 6.1 & 4.2 & 2.3 & 0.5 \\
\hline $18: 1 n-9$ & 11.9 & 13.6 & 15.1 & 16.0 & 17.0 \\
\hline $18: 1 n-7$ & 3.3 & 2.6 & 2.2 & 1.6 & 1.0 \\
\hline $20: 1 n-9$ & 17.9 & 13.1 & 9.0 & 5.0 & 1.1 \\
\hline $22: 1 n-11$ & 13.3 & 10.1 & 7.1 & 4.3 & 1.1 \\
\hline $22: 1 n-9$ & 2.1 & 1.5 & 1.0 & 0.5 & 0.1 \\
\hline Total monoenes ${ }^{2}$ & 58.4 & 48.4 & 39.6 & 30.5 & 21.1 \\
\hline $18: 2 n-6$ & 4.2 & 7.4 & 9.8 & 12.3 & 15.1 \\
\hline $20: 4 n-6$ & 0.2 & 0.2 & 0.1 & 0.1 & 0.1 \\
\hline Total $n-6^{3}$ & 5.0 & 8.0 & 10.2 & 12.6 & 15.2 \\
\hline $18: 3 n-3$ & 0.9 & 14.0 & 25.6 & 37.8 & 50.4 \\
\hline $18: 4 n-3$ & 2.9 & 2.1 & 1.6 & 0.9 & 0.2 \\
\hline $20: 5 n-3$ & 5.9 & 4.6 & 3.5 & 2.2 & 1.0 \\
\hline $22: 6 n-3$ & 5.0 & 4.0 & 3.4 & 2.4 & 1.5 \\
\hline Total $n-3^{4}$ & 15.7 & 25.6 & 34.6 & 43.7 & 53.3 \\
\hline Total PUFA & 21.7 & 34.4 & 45.3 & 56.5 & 68.5 \\
\hline$n-3 / n-6$ & 3.1 & 3.2 & 3.4 & 3.5 & 3.5 \\
\hline Astaxanthin (mg/kg) & 56.9 & 61.8 & 66.6 & 72.2 & 68.7 \\
\hline
\end{tabular}

28 Includes 15:0, 17:0, 20:0 and 22:0. ${ }^{2}$ Includes 16:1n-9, 20:1n-11, 20:1n-7, 22:1n-13 and

$2924: 1 .{ }^{3}$ Includes 20:2n-6, 20:3n-6 and 22:5n-6. ${ }^{4}$ Includes 20:3n-3, 20:4n-3 and 22:5n-3. 


\section{TABLE 2.}

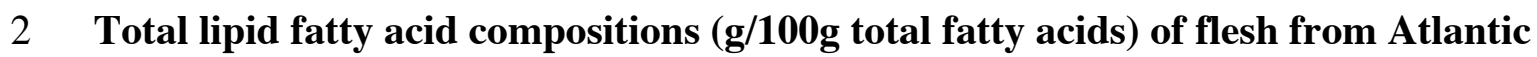
3 salmon fed the linseed oil experimental diets for 40 weeks.

Fatty acid

FO $25 \% \mathrm{LO}$

\section{(a)}

14:0

$4.7 \pm 0.2^{\mathrm{a}} \quad 3.9 \pm 0.1^{\mathrm{b}}$

$50 \% \mathrm{LO}$

$75 \% \mathrm{LO}$

$100 \%$ LO

7

16:0

$$
12.9 \pm 0.2^{\mathrm{a}}
$$

$11.7 \pm 0.2^{\mathrm{b}}$

$10.7 \pm 0.3^{\mathrm{c}}$

$0.8 \pm 0.1^{\mathrm{d}}$

$0.7 \pm 0.1^{\mathrm{d}}$

18:0

$$
1.9 \pm 0.1^{\mathrm{e}}
$$

$2.3 \pm 0.0^{\mathrm{d}}$

$2.8 \pm 0.1^{\mathrm{c}}$

$9.6 \pm 0.2^{\mathrm{d}}$

$8.3 \pm 0.2^{\mathrm{e}}$

9 Total saturates ${ }^{1}$

$19.9 \pm 0.3^{\mathrm{a}}$

$18.1 \pm 0.2^{\mathrm{b}}$

$16.5 \pm 0.4^{\mathrm{c}}$

$3.1 \pm 0.0^{\mathrm{b}}$

$3.6 \pm 0.1^{\mathrm{a}}$

$10 \quad 16: 1 n-7$

$7.5 \pm 0.2^{\mathrm{a}}$

$5.5 \pm 0.1^{\mathrm{b}}$

$4.0 \pm 0.1^{\mathrm{c}}$

$14.7 \pm 0.2^{\mathrm{d}}$

$12.7 \pm 0.3^{\mathrm{e}}$

$11 \quad 18: 1 \mathrm{n}-9$

$16.0 \pm 0.4^{\mathrm{c}}$

$17.4 \pm 0.3^{\mathrm{b}}$

$17.6 \pm 0.3^{\mathrm{b}}$

$2.3 \pm 0.1^{\mathrm{d}}$

$0.8 \pm 0.0^{\mathrm{e}}$

$12 \quad 18: 1 n-7$

$3.8 \pm 0.0^{\mathrm{a}}$

$3.4 \pm 0.3^{\mathrm{b}}$

$2.5 \pm 0.1^{\mathrm{c}}$

$17.6 \pm 0.3^{\mathrm{b}}$

$18.6 \pm 0.3^{\mathrm{a}}$

$13 \quad 20: 1 n-9$

$16.6 \pm 0.3^{\mathrm{a}}$

$11.9 \pm 0.2^{\mathrm{b}}$

$8.7 \pm 0.1^{\mathrm{c}}$

$2.2 \pm 0.1^{\mathrm{d}}$

$1.3 \pm 0.1^{\mathrm{e}}$

$14 \quad 22: 1 \mathrm{n}-11$

$$
9.9 \pm 0.1^{\mathrm{a}}
$$

$$
7.3 \pm 0.3^{\mathrm{b}}
$$

$5.4 \pm 0.1^{\mathrm{c}}$

$4.8 \pm 0.0^{\mathrm{d}}$

$1.6 \pm 0.1^{\mathrm{e}}$

Total mo $18: 2 \mathrm{n}-6$

$48.4 \pm 0.6^{b}$

$40.3 \pm 0.4^{\mathrm{c}}$

$3.0 \pm 0.0^{\mathrm{d}}$

$1.1 \pm 0.1^{\mathrm{e}}$

17

20:2n-6

$$
3.9 \pm 0.1^{\mathrm{e}}
$$

$6.8 \pm 0.1^{\mathrm{d}}$

$8.6 \pm 0.1^{\mathrm{c}}$

$31.5 \pm 0.3^{\mathrm{d}}$

$24.2 \pm 0.4^{\mathrm{e}}$

18

20:4n-6

$0.4 \pm 0.0^{\mathrm{d}}$

$0.5 \pm 0.0^{\mathrm{c}}$

$0.6 \pm 0.0^{\mathrm{b}}$

$11.0 \pm 0.1^{\mathrm{b}}$

$13.1 \pm 0.2^{\mathrm{a}}$

19 Total n- $6^{3}$

$0.3 \pm 0.1^{\mathrm{a}}$

$0.2 \pm 0.0^{\mathrm{ab}}$

$0.2 \pm 0.0^{\mathrm{ab}}$

$0.6 \pm 0.0^{\mathrm{b}}$

$0.7 \pm 0.0^{\mathrm{a}}$

20

18:3n-3

$4.9 \pm 0.2^{\mathrm{e}}$

$7.8 \pm 0.1^{\mathrm{d}}$

$9.8 \pm 0.2^{\mathrm{c}}$

$0.1 \pm 0.1^{\mathrm{b}}$

$0.1 \pm 0.0^{\mathrm{b}}$

21

$18: 4 n-3$

$0.8 \pm 0.2^{\mathrm{e}}$

$11.5 \pm 0.3^{\mathrm{d}}$

$20.1 \pm 0.3^{\mathrm{c}}$

$11.8 \pm 0.1^{\mathrm{b}}$

$14.0 \pm 0.1^{\mathrm{a}}$

22 20:3n-3

$1.5 \pm 0.1^{\mathrm{a}}$

$1.3 \pm 0.1^{\mathrm{b}}$

$1.3 \pm 0.1^{\mathrm{b}}$

$30.1 \pm 0.4^{\mathrm{b}}$

$38.7 \pm 0.8^{\mathrm{a}}$

\section{$23 \quad 20: 4 n-3$}

$0.1 \pm 0.0^{\mathrm{e}}$

$0.7 \pm 0.0^{\mathrm{d}}$

$1.4 \pm 0.1^{\mathrm{c}}$

$1.2 \pm 0.1^{\mathrm{b}}$

$1.2 \pm 0.1^{\mathrm{b}}$

24

20:5n-3

$1.2 \pm 0.0^{\mathrm{d}}$

$1.4 \pm 0.0^{\mathrm{c}}$

$1.5 \pm 0.0^{\mathrm{bc}}$

$2.1 \pm 0.1^{\mathrm{b}}$

$2.7 \pm 0.1^{\mathrm{a}}$

$25 \quad 22: 5 n-3$

$4.3 \pm 0.2^{\mathrm{a}}$

$3.0 \pm 0.1^{\mathrm{b}}$

$2.5 \pm 0.1^{\mathrm{c}}$

$1.6 \pm 0.0^{\mathrm{b}}$

$1.8 \pm 0.1^{\mathrm{a}}$

26

22:6n-3

$1.5 \pm 0.0^{\mathrm{a}}$

$1.1 \pm 0.1^{\mathrm{b}}$

$1.0 \pm 0.0^{\mathrm{b}}$

$1.8 \pm 0.1^{\mathrm{d}}$

$1.3 \pm 0.1^{\mathrm{e}}$

27 Total n-3

$8.1 \pm 0.7^{\mathrm{a}}$

$6.1 \pm 0.7^{\mathrm{b}}$

$5.3 \pm 0.4^{\mathrm{bc}}$

$0.6 \pm 0.1^{\mathrm{c}}$

$0.4 \pm 0.1^{\mathrm{d}}$

28 Total PUFA

$17.5 \pm 0.7^{\mathrm{e}}$

$25.2 \pm 0.7^{\mathrm{d}}$

$33.1 \pm 0.6^{\mathrm{c}}$

$4.3 \pm 0.5^{\mathrm{c}}$

$3.1 \pm 0.2^{\mathrm{d}}$

29

n-3/n-6

$22.9 \pm 0.8^{\mathrm{e}}$

$33.4 \pm 0.7^{\mathrm{d}}$

$43.1 \pm 0.7^{\mathrm{c}}$

$41.7 \pm 0.3^{\mathrm{b}}$

$49.1 \pm 0.6^{\mathrm{a}}$

$$
3.6 \pm 0.4 \quad 3.2 \pm 0.3
$$

$3.4 \pm 0.3$

$53.7 \pm 0.3^{\mathrm{b}}$

$66.1 \pm 0.7^{\mathrm{a}}$

30

31

32

Values are mean $\pm \mathrm{SD}, \mathrm{n}=6 .{ }^{1}$ Includes 15:0, 17:0, 20:0 and 22:0. ${ }^{2}$ Includes 16:1n-9, 
$1<0.05$ are shown as 0.0. Values in the same row with a different superscript letter are 2 significantly different $(\mathrm{P}<0.05)$.

3 
1 TABLE 3.

2 Correlation coefficients and slopes from plots of dietary fatty acid concentrations vs.

3 flesh fatty acid concentrations including the difference $(\Delta)$ between diet and flesh

4 fatty acid values for salmon fed $100 \%$ FO, $50 \%$ LO and $100 \%$ LO diets.

5

7

Fatty acid

Correlation

Correlation

Slope

$\Delta 100 \%$ FO

$\Delta 50 \%$ LO

$\Delta 100 \%$ LO

$8 \quad 16: 0$ coefficient $\left(\mathrm{r}^{2}\right)$

9

9 Total saturates

0.997

$0.78 \pm 0.02$

0.8

1.4

2.2

10

$18: 1 n-9$

0.998

$0.77 \pm 0.02$

0.0

1.4

2.2

10

11

$20: 1 n-9$

0.876

$0.43 \pm 0.09$

4.1

2.5

1.6

12 22:1n-11

0.999

$0.89 \pm 0.02$

$-1.3$

$-0.3$

0.5

12 22:1n-11

0.997

$0.73 \pm 0.02$

$-3.4$

$-1.7$

0.0

$13 \quad 18: 2 n-6$

0.999

$0.85 \pm 0.02$

$-0.3$

$-1.2$

$-2.0$

$14 \quad 18: 3 n-3$

0.999

$0.77 \pm 0.01$

$-0.1$

$-5.5$

$-11.7$

$15 \quad 20: 5 n-3$

0.966

$0.59 \pm 0.06$

$-1.6$

$-1.0$

0.3

$16 \quad 22: 6 n-3$

0.979

$1.37 \pm 0.12$

3.1

1.9

1.6

17 Fatty acid concentrations are g fatty acid/100g total fatty acids in muscle and diets.

18 Negative $\Delta$ values indicate lower values in muscle compared with diet, whereas positive

19 values indicate accumulation in muscle relative to diet.

20 


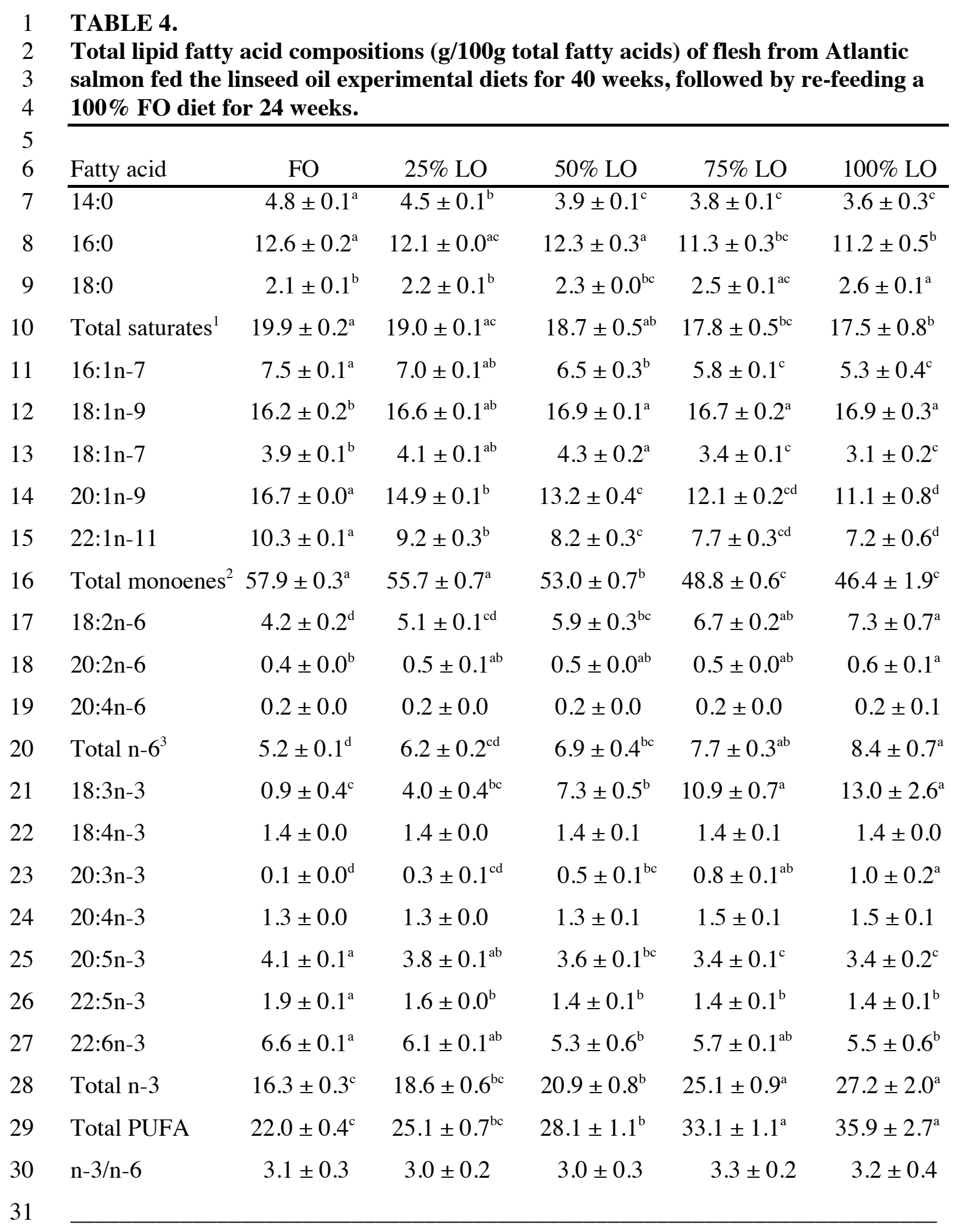


1 Values are mean $\pm \mathrm{SD}, \mathrm{n}=3 .{ }^{1}$ Includes 15:0, 17:0, 20:0 and 22:0. ${ }^{2}$ Includes 16:1n-9, $220: 1 \mathrm{n}-11,20: 1 \mathrm{n}-7,22: 1 \mathrm{n}-13$ and $24: 1 .{ }^{3}$ Includes $18: 3 \mathrm{n}-6,20: 3 \mathrm{n}-6$ and 22:5n-6. SD values

$3<0.05$ are shown as 0.0. Values in the same row with a different superscript letter are 4 significantly different $(\mathrm{P}<0.05)$. 
1 Fig. 1.

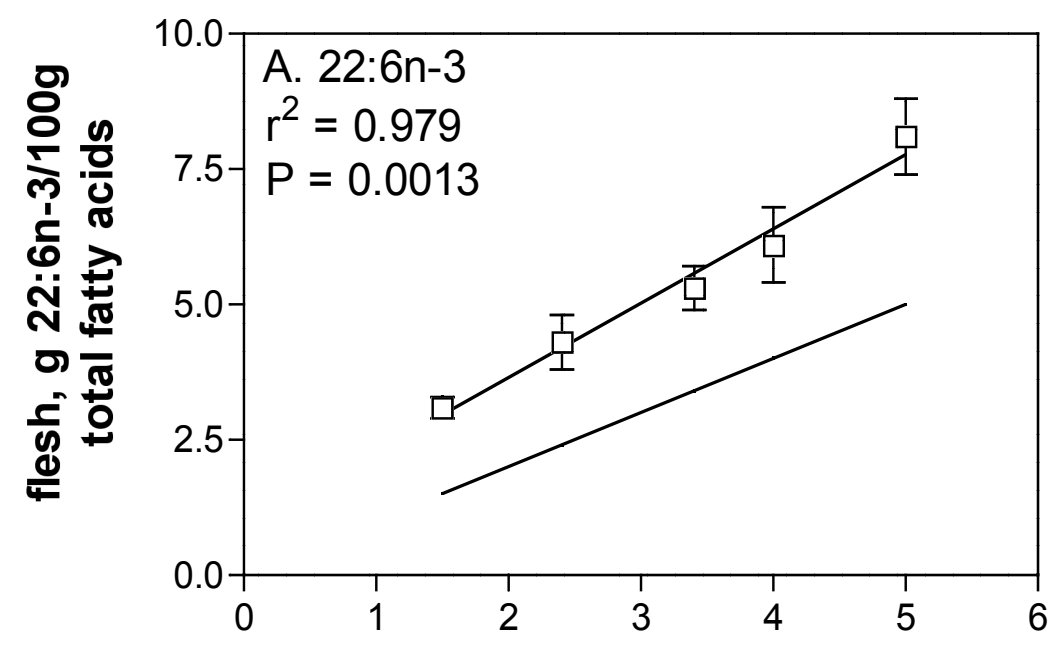

2

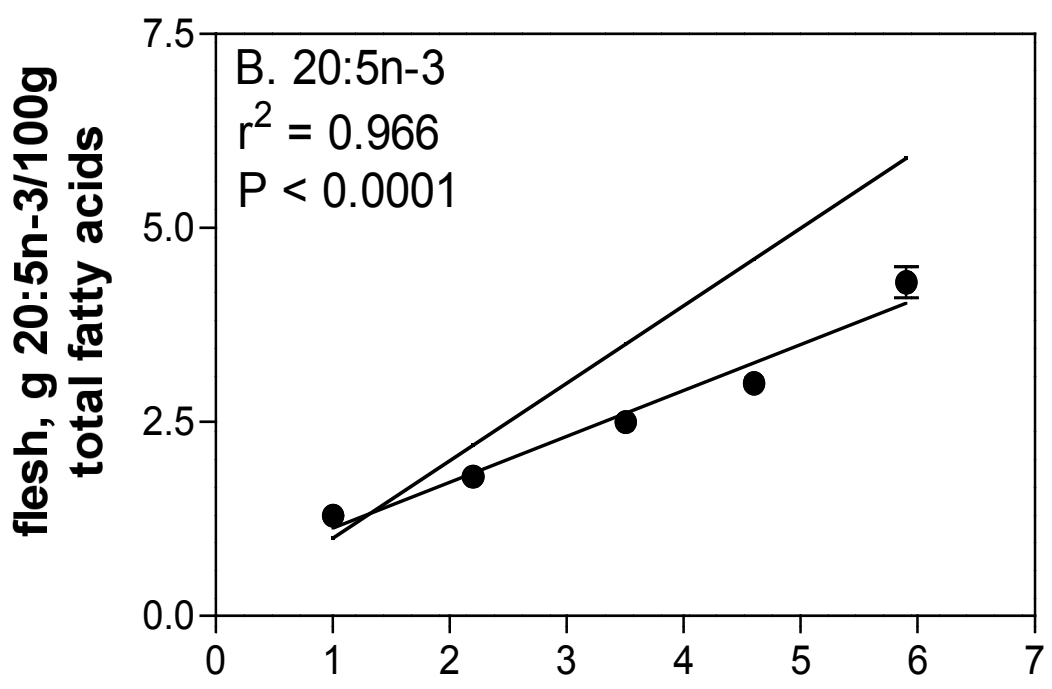

3

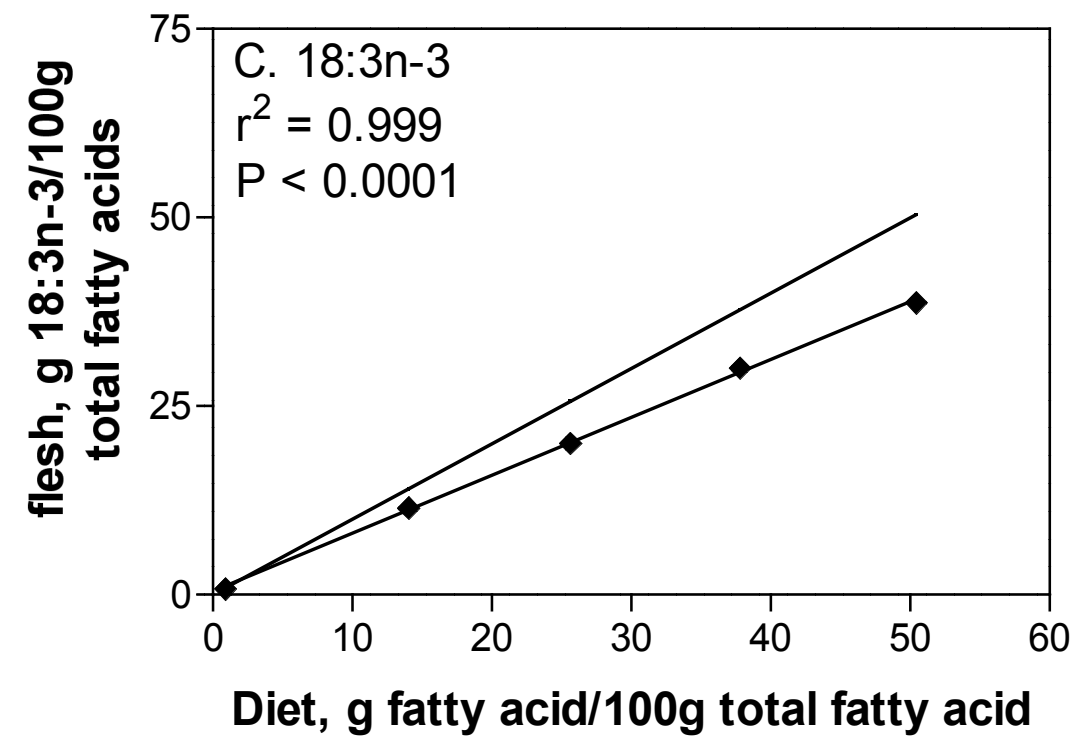


$1 \quad$ Fig. 2.

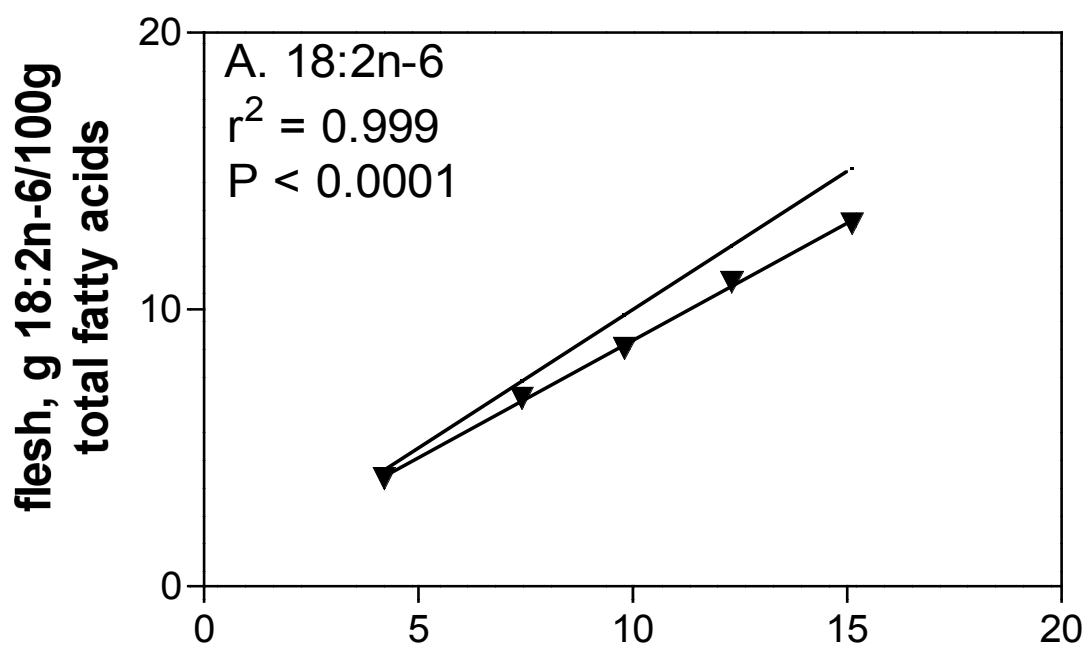

2

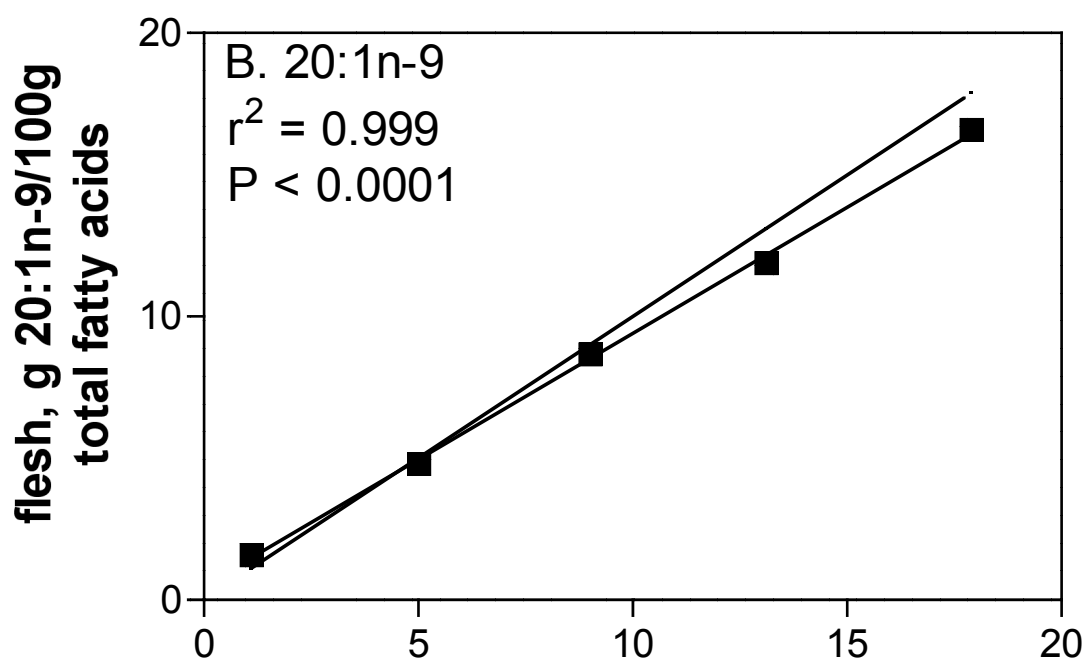

3

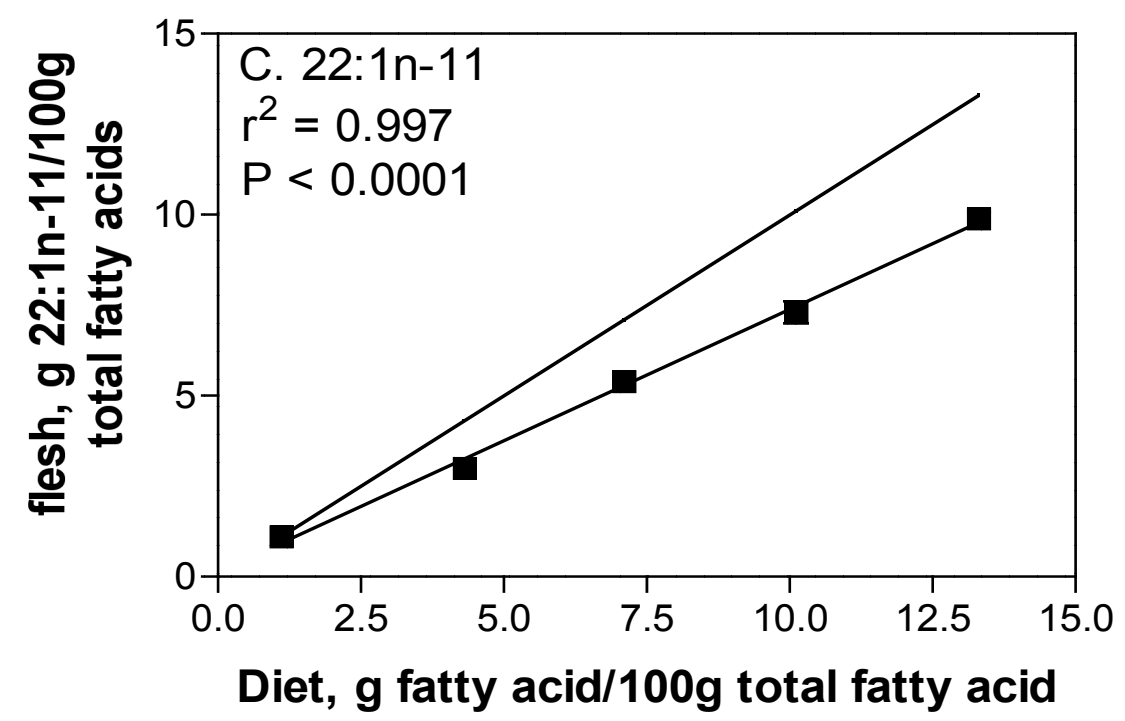

4
5 
1 Fig. 3.

2

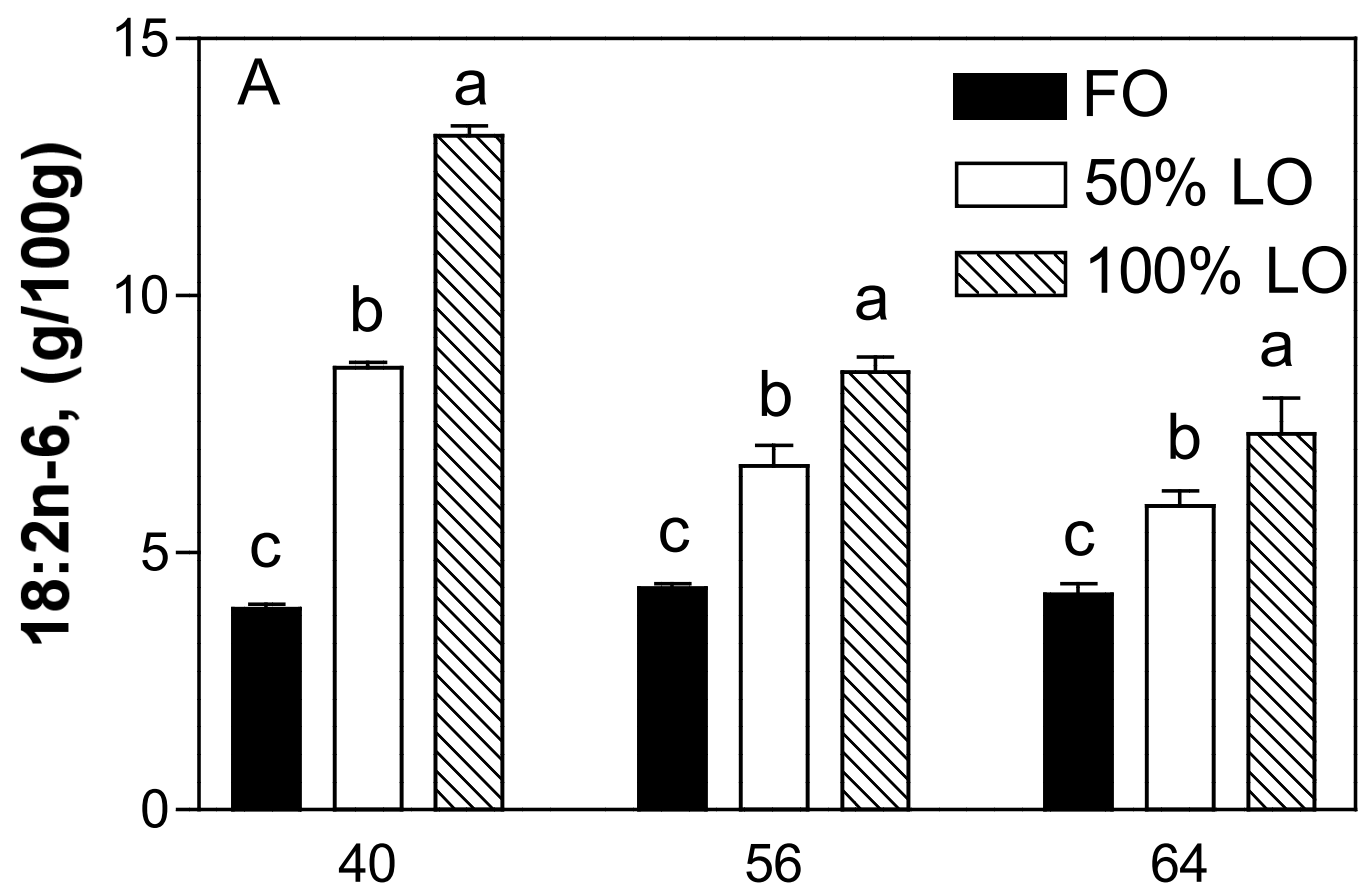

3

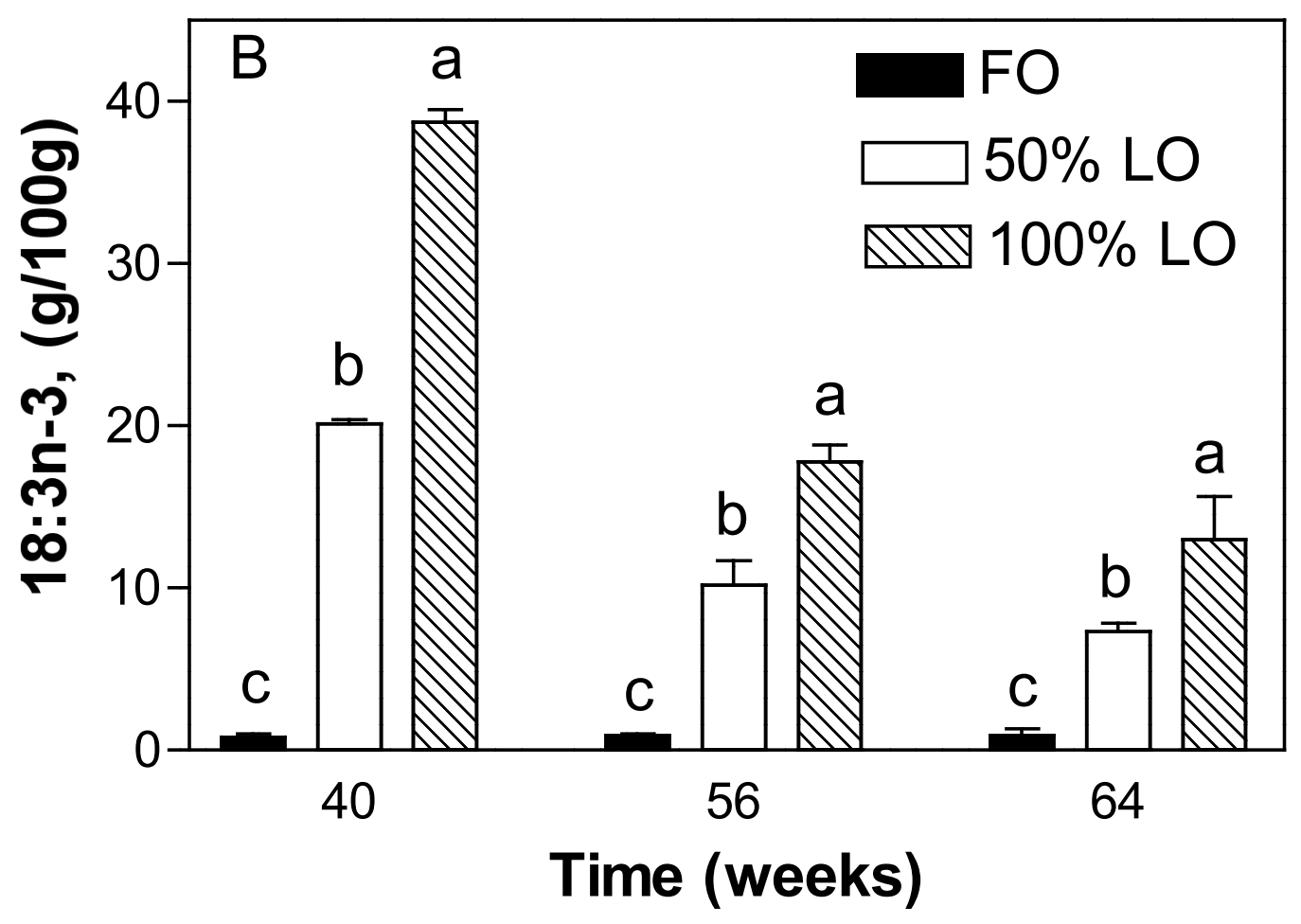


1 Fig. 4

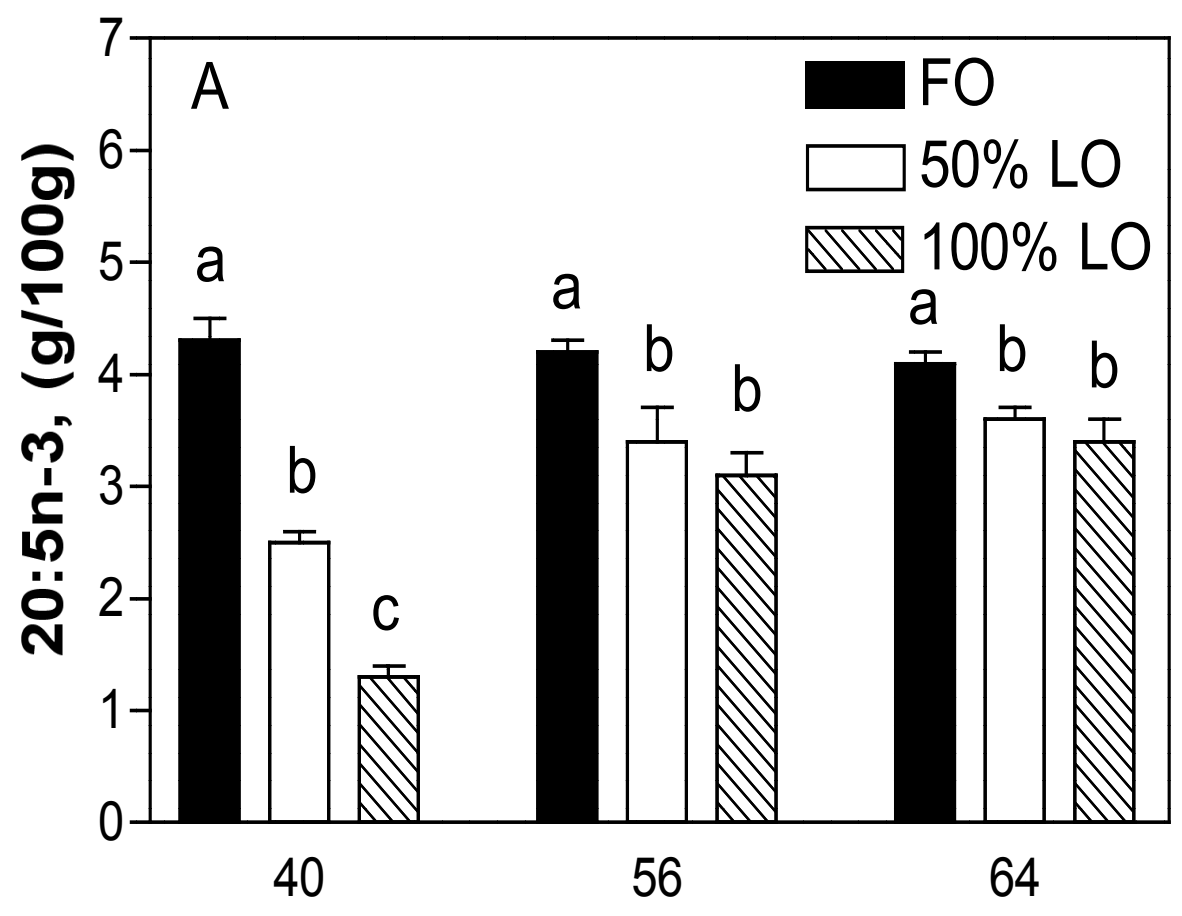

2

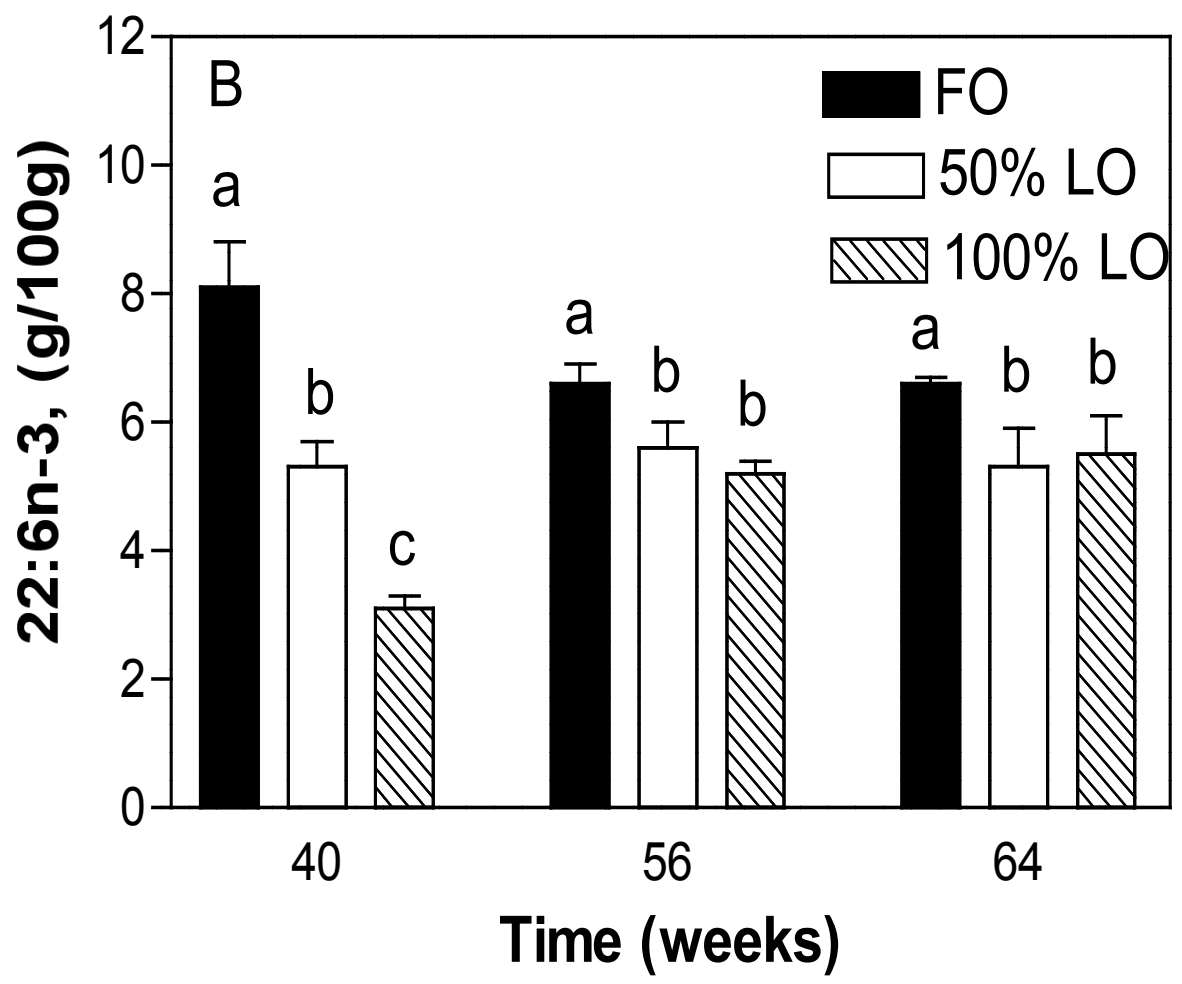

